Trauma Surgery \& Acute Care Open

\title{
Open abdomen critical care management principles: resuscitation, fluid balance, nutrition, and ventilator management
}

\author{
Elizabeth Chabot, ${ }^{1}$ Ram Nirula ${ }^{2}$
}

\begin{abstract}
'School of Medicine, University of Utah, Salt Lake City, Utah, USA

2Department of Surgery, University of Utah, Salt Lake City, Utah, USA
\end{abstract}

Correspondence to Dr Ram Nirula, Department of Surgery, University of Utah, Salt Lake City, UT 84108, USA; r. nirula@hsc.utah.edu

Received 3 January 2017 Revised 15 April 2017 Accepted 16 May 2017
To cite: Chabot E, Nirula R. Trauma Surg Acute Care Open 2017;2:1-9.

\begin{abstract}
The term "open abdomen" refers to a surgically created defect in the abdominal wall that exposes abdominal viscera. Leaving an abdominal cavity temporarily open has been well described for several indications, including damage control surgery and abdominal compartment syndrome. Although beneficial in certain patients, the act of keeping an abdominal cavity open has physiologic repercussions that must be recognized and managed during postoperative care. This review article describes these issues and provides guidelines for the critical care physician managing a patient with an open abdomen.
\end{abstract}

\section{INTRODUCTION}

The term "open abdomen" (OA) refers to a surgically created defect in the abdominal wall that exposes abdominal viscera. Leaving an abdominal cavity temporarily open has been well described for several indications, including damage control surgery (DCS) and abdominal compartment syndrome (ACS). Although beneficial in certain patients, the act of keeping an abdominal cavity open has physiologic repercussions that must be recognized and managed during postoperative care. This review article describes these issues and provides guidelines for the critical care physician managing a patient with an OA.

\section{INDICATIONS}

There are several disease processes that may be managed by leaving a patient with an OA. These indications can be separated into three broad categories: anatomic, physiologic, and logistic reasons. ${ }^{1}$ Anatomic reasons pertain to the inability to bring fascial edges together, physiologic reasons relate to systemic dysfunction, and logistic reasons refer to anticipated abdominal reintervention. The two most common indications for using the OA technique are DCS after trauma and ACS. Other specific disease processes that may be managed with this technique include acute pancreatitis, intra-abdominal sepsis, and ruptured abdominal aortic aneurysm (AAA).

\section{DAMAGE CONTROL SURGERY}

In trauma, DCS refers to performing an initial laparotomy in the hemodynamically unstable patient with the goal of quickly temporizing life-threatening injuries. It originated with therapeutic packing to manage hemorrhage from liver injuries in the early 1900s and has evolved to the technique used today. ${ }^{2}$ Once hemorrhage and spillage of enteric contents have been controlled, the patient is assessed for acidosis, coagulopathy, and hypothermia. If elements of this lethal triad are present, the patient may be left with an $\mathrm{OA}$ and resuscitated in an intensive care unit (ICU) until they are medically able to tolerate a more lengthy operative procedure for definitive repair of injuries and abdominal closure. $^{3-6}$ The Eastern Association for the Surgery of Trauma (EAST) practice management committee performed a literature review of the management of the OA in trauma and emergency general surgery in 2010. According to their published guidelines, level III evidence exists to support the use of the OA technique in a trauma setting in the presence of acidosis $(\mathrm{pH}<7.2)$, hypothermia (temperature $<35^{\circ} \mathrm{C}$ ), and clinical coagulopathy with transfusion of $>10$ units of red blood cells (RBCs). ${ }^{?}$

Although DCS has been well accepted into trauma practice during the past several decades, there are no large randomized controlled studies comparing it directly to initial definitive repair. Recent studies warn against its overuse and exposure to unnecessary complications such as ileus (13\%), anastomotic leak (7\%), fascial dehiscence (11\%), and surgical site infections (19\%). ${ }^{89}$ Attention is now being focused on the use of damage control resuscitation (DCR) as an important cofactor to DCS. DCR specifically refers to the early use of blood products and limiting unnecessary crystalloids in trauma to prevent the onset of the lethal triad of acidosis, coagulopathy, and hypothermia. The implementation of transfusion protocols based on a trauma patient's presenting hemodynamic status has led to a reduction in organ failure, utilization of blood products, and 30-day mortality. ${ }^{10-14}$ One study found that an institutional protocol aimed at the early administration of blood products in a ratio of 3:2 RBC:FFP and 5:1 RBC:platelets for patients in hemorrhagic shock improved 30 -day survival $(56.8 \%$ vs $37.6 \%$, $\mathrm{p}=0.001)$ and had a $51 \%$ odds reduction of severe sepsis. The patients in the protocolized arm of the study also had a significantly lower incidence of ACS ( $0 \%$ vs $7 \%, \mathrm{p}<0.001) .{ }^{10}$ As increased utilization of this principle is used, fewer patients may reach the parameters to warrant DCS resulting in fewer OAs. ${ }^{15}$

\section{ABDOMINAL COMPARTMENT SYNDROME}

ACS refers to the constellation of symptoms that occur when intra-abdominal pressure is increased 
to the level of organ dysfunction. In 2007, the World Consensus for ACS (WCACS) provided standard definitions for the diagnosis and management of ACS. ${ }^{16} 17$ Normal intra-abdominal pressure as measured via bladder catheterization is approximately $5 \mathrm{~mm} \mathrm{Hg}$ to $7 \mathrm{~mm} \mathrm{Hg}$. Intra-abdominal hypertension (IAH) is defined by sustained pressures greater than $12 \mathrm{~mm} \mathrm{Hg}$ and can be graded according to severity. ACS is a sustained intra-abdominal pressure $>20 \mathrm{~mm} \mathrm{Hg}$ that is associated with new organ dysfunction. The abdominal perfusion pressure (mean arterial pressure- intra-abdominal pressure) has been shown to correlate with survival when maintained at levels greater than $50 \mathrm{~mm} \mathrm{Hg}$ to $60 \mathrm{~mm} \mathrm{Hg}$, but level I evidence examining this as an end point of resuscitation has yet to be obtained. ${ }^{17} 18$

Risk factors for the development of ACS in patients from both medical and surgical ICUs in a large multicenter prospective study included abdominal surgery, high-volume fluid resuscitation, ileus, and dysfunction of the pulmonary, renal, or hepatic systems. ${ }^{19}$ The WCACS recommends that if two or more risk factors for ACS are present, a baseline intra-abdominal pressure should be obtained. If this demonstrates IAH, pressures should be serially measured, although the optimal frequency has not been identified. ${ }^{17}$ In addition, non-surgical strategies to control intra-abdominal pressure should be considered and initiated where appropriate. These include the evacuation of intraluminal contents via nasogastric and/or rectal tubes, decreasing rate of enteral input, administering promotility agents and enemas, and considering colonoscopic decompression if clinically indicated. There are no prospective trials to quantify the benefit of these maneuvers in their ability to prevent ACS, but their ability to mitigate pathologic intestinal distension is a theoretical benefit for reducing intra-abdominal pressure.

Interestingly, a novel approach to reducing IAH was identified in a prospective, blinded evaluation of thoracic epidurals in surgically critically ill patients with trauma performed by Hakobyan. In this study, patients with epidurals had significantly decreased intra-abdominal pressures from a mean of $16.8 \mathrm{~mm} \mathrm{Hg}$ in the morphine analgesia group to $6.3 \mathrm{~mm} \mathrm{Hg}$ in the epidural group. ${ }^{20}$ This was associated with increased abdominal perfusion pressure and did not result in hemodynamic compromise. These patients received their epidurals after their initial resuscitation, which limits the use of this modality to patients who have not developed early ACS. Further this was not a randomized trial, and therefore selection bias exists and did not provide data on the subsequent need for OA or organ failure.

Another non-surgical maneuver includes percutaneous catheter drainage of any space-occupying fluid collections or resuscitation-induced ascites. ${ }^{21} 22$ In 2011, Cheatham published results from a case-control comparison of percutaneous drainage versus traditional open abdominal decompression. Their approach was to perform bedside abdominal ultrasound, and in those patients with large intra-abdominal fluid, a percutaneous drainage catheter was placed. They found that potentially $81 \%$ of percutaneous drainage patients had improvement in APP and organ dysfunction and successfully avoided laparotomy. Risk factors for failure of percutaneous drainage included drainage of less than $1 \mathrm{~L}$ of fluid or a decrease of less than $9 \mathrm{~mm} \mathrm{Hg}$ in the first 4 hours after catheter placement, suggesting that those patients should rapidly proceed to open abdominal decompression. ${ }^{23}$

Fluid management is of particular concern and must be tailored to maintain adequate abdominal perfusion pressures but avoid volume overload. Both hypertonic saline and colloid as resuscitative solutions have demonstrated reduced intra-abdominal pressures when compared with isotonic fluid in select patient populations. ${ }^{24} 25$ For example, only $14 \%$ of patients receiving hypertonic saline resuscitation developed IAH compared with $50 \%$ of patients receiving lactated Ringer (LR) solution in patients with burn injuries. ${ }^{24}$ Another burn study found that adding FFP to crystalloid resuscitation reduced the total volume of fluid infused $(0.21 \mathrm{~L} / \mathrm{kg}$ vs $0.26 \mathrm{~L} / \mathrm{kg}, \mathrm{p}<0.005)$, which correlated with a smaller rise in IAP. ${ }^{25}$ These resuscitation strategies should be considered in patients with IAH to decrease progression to ACS. ${ }^{17}$ Neuromuscular blockade with cisatracurium boluses has also been demonstrated to temporarily reduce intra-abdominal pressure (from $18 \mathrm{~mm} \mathrm{Hg}$ to $14 \mathrm{~mm} \mathrm{Hg}$ with a duration of effect of 2 hours), but given the risks of prolonged paralysis, it should be used sparingly. ${ }^{26} 27$

If the above-mentioned medical interventions fail to reduce intra-abdominal pressures, or if the patient progresses to fulminant ACS with evidence of organ failure, surgical intervention is recommended. ${ }^{7161728}$ With elevated intra-abdominal pressure, venous return is impeded, and patients may develop hypotension, pulmonary failure secondary to increased airway pressures, and renal failure with oliguria. Abdominal decompression to relieve IAH can result in immediate improvement in lung compliance and tidal volume $(432 \mathrm{~mL}$ before decompression to $575 \mathrm{~mL}$ after decompression), increased cardiac index $(4.8 \mathrm{~L} / \mathrm{min}$ to $7.0 \mathrm{~L} / \mathrm{min})$, and improved urine output $(23 \mathrm{~mL} / \mathrm{h}$ to $358 \mathrm{~mL} / \mathrm{h}) .{ }^{29}$ A significant drop in central venous pressure (CVP) has also been identified. ${ }^{30}$ The intensivist must be aware of these hemodynamic changes and be prepared to adjust the ventilator or resuscitate accordingly when bedside decompression is performed.

There is also evidence that ACS can cause elevations in intracranial pressure (ICP); subsequent abdominal decompression can help to reduce ICP, which is particularly beneficial for patients with concomitant traumatic brain injury. ${ }^{31}$ In 2004 , Joseph et al published results from 17 patients with trauma with refractory intracranial hypertension despite both maximal medical therapy and decompressive craniectomy. Decompressive laparotomy was performed in these patients with the sole indication of intracranial hypertension. Although none of these patients had evidence of ACS, mean ICPs were reduced by $10 \mathrm{~mm} \mathrm{Hg}$. Overall survival was $64.7 \%$, with non-survivors experiencing only a transient reduction in ICP prior to their death. ${ }^{32}$

ACS was identified as the only level 1 indication for an OA by the EAST guidelines. They also recommend consideration of prophylactic OA or leaving the abdomen open at the time of initial laparotomy to prevent subsequent ACS in patients who have received $>10$ units of RBCs or $>15 \mathrm{~L}$ of crystalloid during their acute resuscitation. If the abdomen is not opened, these patients should be carefully monitored with serial bladder pressures for the development of ACS. ${ }^{73} 34$

Several studies have specifically examined ACS in the setting of acute pancreatitis. The major mechanisms leading to IAH in this disease process include peripancreatic inflammation, visceral edema secondary to resuscitation, and ileus. Early relief of ACS clearly improves outcomes, but the best way to accomplish this remains controversial. ${ }^{75}$ For example, catheter drainage of ascites to improve abdominal perfusion pressure has been reported. ${ }^{36-39}$ A 2006 randomized controlled study from Sun et al found a significant reduction in hospital length of stay and a trend toward reduced mortality $(20.7 \%$ to $10 \%)$ in patients with acute pancreatitis and ACS who underwent percutaneous drainage versus decompressive laparotomy. ${ }^{36}$ For patients who have persistent organ dysfunction and $\mathrm{IAH}$ despite catheter drainage, surgical decompression is mandated..$^{7638}$ 


\section{Intra-abdominal sepsis}

An OA has also been described as a treatment option in the management of intra-abdominal sepsis. ${ }^{40}$ As with all infectious processes, source control remains the primary goal in management. A laparotomy provides the ability to drain infection, debride necrotic material, repair intestinal injury, and perform additional maneuvers necessary for source control. Data suggest that the application of "damage control surgery" in trauma to emergency general surgery patients with an acute intra-abdominal process may reduce mortality. For patients with surgical abdominal sepsis causing acidosis, hemodynamic instability, or other significant systemic disturbances, quickly controlling contamination and then placing a temporary abdominal dressing for further resuscitation in the ICU and a planned second-stage operation is likely beneficial. ${ }^{41-43}$ One recent small, retrospective study examined the application of damage control for patients with generalized peritonitis secondary to perforated diverticulitis. Although there was no difference in postoperative mortality, patients who underwent DCS followed by a second-look laparotomy with closure 24 hours to 48 hours later had a reduced stoma rate $(83 \%$ vs $47 \%$, $\mathrm{p}=0.038) .{ }^{44}$ The exact parameters when to consider DCS for the emergency general surgery patient are not as well outlined as in the trauma setting. ${ }^{45} 46$ A retrospective study of general surgery patients who underwent DCS found that indications should include severe sepsis/septic shock, elevated lactate $>3$, acidosis $(\mathrm{pH}<7.25)$, age $>70$ years, male gender, and multiple pre-existing comorbidities. These specific variables were independent predictors of mortality as determined by a logistic regression analysis. ${ }^{46}$ Both outcomes and indications for damage control operations in emergency general surgery are areas that would benefit from further research.

In patients with bacterial peritonitis who have had definitive repair of intestinal defects, the decision to leave the abdomen open remains controversial. Proposed benefits include the prevention of ACS in those patients who may require high-volume resuscitation and the ability to undergo repeat washouts to reduce bacterial contamination and to ensure that source control is maintained. It has also been hypothesized that continuously removing cytokine-laden peritoneal fluid may reduce the systemic inflammatory response, although a recent randomized controlled study demonstrated no difference in serum interleukin-6 levels with peritoneal fluid drainage. ${ }^{478}$ A prospective study is currently underway to further investigate this hypothesis by serially examining inflammatory components in the peritoneal fluid and serum of patients with a temporary abdominal dressing after damage control laparotomy. ${ }^{49}$

In specific regards to outcomes, studies have not shown a clear benefit of routinely leaving an abdomen open for secondary peritonitis to perform subsequent washout. ${ }^{43}$ Robledo et al performed a randomized trial in 2007 in patients with secondary peritonitis in which patients were randomized to either immediate fascial closure after the primary operation or were left with an OA. The two groups were well matched in regards to sex, age, severity of illness, and etiology of peritonitis. The investigators found a non-significant trend toward reduced mortality rates with primary closure (30\% closed vs 55\% open) as well as a reduced length of hospital stay (3.3 weeks vs 4.1 weeks). Rates of acute renal failure, respiratory failure, intra-abdominal infection, and gastrointestinal fistulas were similar between the two groups. ${ }^{41}$ This mirrors earlier findings from a retrospective review article by Adkins in which no significant difference in mortality between open or closed management of peritonitis was identified. The authors noted that the study of this particular question is made difficult by the heterogeneity of the disease process. ${ }^{50}$

\section{ABDOMINAL AORTIC ANEURYSM}

Patients with a ruptured AAA are at risk of developing IAH and ACS secondary to volume resuscitation, space occupying hematomas, and reperfusion injuries. In 2006, Djavani demonstrated that $29 \%$ of patients undergoing laparotomy for a ruptured AAA developed IAH. ${ }^{51}$ In 2011, Gidlund showed that EVAR for ruptured AAAs had a similar rate of IAH with $34 \%$ of patients developing bladder pressures $>20 \mathrm{~mm} \mathrm{Hg.}{ }^{51}$ Rasmussen was the first to identify risk factors for the development of ACS in this patient population. He found that preoperative shock of systolic blood pressure $<90 \mathrm{~mm} \mathrm{Hg}$ for $>18 \mathrm{~min}$, preoperative cardiac arrest, hypothermia $\left(<33^{\circ} \mathrm{C}\right)$, severe acidosis $(\mathrm{BD}>13)$, and massive intraoperative resuscitation $(>3.5 \mathrm{~L} / \mathrm{h})$ were significant risk factors and proposed elective delayed fascial closure for these patients. ${ }^{52}$ In a 2009 retrospective review, Kimball et al specifically studied open versus closed initial management of ruptured AAA by comparing two separate time periods (19892000 where primary closure predominated ruptured AAA repair versus 2000-2005 when DCS was implemented). Although there was not a statistically significant overall difference in 24 hours mortality ( $2 \%$ open vs $10 \%$ closed, $\mathrm{p}=0.13)$, patients managed with an OA tended to have high-risk characteristics as defined by preoperative hypotension, estimated blood loss (EBL) $>6 \mathrm{~L}$, or $>12 \mathrm{~L}$. When this was accounted for, there was a significant reduction in 24 hours mortality for open management ( $0 \%$ vs $21 \%, \mathrm{p}=0.03) .{ }^{53}$ It has been shown that there is a strong correlation between IAH and both colonic ischemia and renal failure in this patient population, so early diagnosis and treatment is essential. ${ }^{515254}$ EAST guidelines recommend using the damage control technique for patients who are at high risk for visceral edema or IAH.

\section{TEMPORARY CLOSURE}

For surgeons, the main objectives in choosing a temporary closure technique are to provide easy re-exploration, to minimize fluid losses, to prevent trauma to the viscera, and to reduce fascial retraction. Many techniques have been described. Today the most common techniques include Wittmann patch (WP) and negative pressure wound therapy (NPWT). WP consists of two sheets of Velcro material that are sewn to the fascial edges after a plastic drape is placed over the viscera. The sheets are then overlapped in a manner to minimize tension but provide a secure closure. With each subsequent operation, the patch can be tightened to prevent fascial retraction. There are several commercial and non-commercial versions of NPWT, but all follow the basic principle of a three-layer closure. A fenestrated plastic sheet is draped over the exposed viscera for protection, a macroporous material (gauze, surgical towel, or sponge) is laid down next with a suction drainage system applied to the superficial layer, and an occlusive adhesive dressing is placed on top. This system significantly reduces evaporation and insensible peritoneal fluid losses and allows the measured peritoneal fluid output to be replaced more precisely when needed. An additional benefit of this temporary closure technique is that it does not need to be sewn to the tissue, a factor that saves both time and trauma to the fascia. Commercially available dressings, including the ABThera dressing, can increase rates of fascial closure when compared with negative pressure dressings fashioned out of laparotomy pads and suction $(89 \%$ vs $59 \%, \mathrm{p}<0.05)$, a finding 
that translates into increased healthcare cost savings when factoring in future hernia repairs despite the increased cost of the ABThera device itself. ${ }^{5-58}$ Historically, NPWT was criticized for its theoretical risk of increasing enterocutaneous fistulas, but this has not been shown to be a statistically significant finding. In 2013, the reported enterocutaneous fistula rate for OAs was not significantly different with NPWT $(13.8 \%)$ compared with non-NPWT $(8.5 \%)$ dressings (RR 0.83 , $95 \%$ CI 0.44 to 1.58$).{ }^{58}$ In regards to the amount of negative pressure that should be applied with NPWT, levels of $-75 \mathrm{~mm} \mathrm{Hg}$ to $-175 \mathrm{~mm} \mathrm{Hg}$ have been reported, but no studies have been performed directly comparing different levels. A porcine model in 2012 demonstrated a correlation with increasing levels of negative pressure and decreasing microvascular blood flow to the intestinal wall. ${ }^{59}$ However, the clinical significance of this is uncertain and must be weighed against the ability of higher levels of negative pressure to more effectively remove intra-abdominal fluid.

\section{ICU MANAGEMENT}

Once the decision for an OA has been made, there are several factors that the intensivist needs to consider when managing these patients postoperatively. Of paramount concern is the management of the initial insult. This refers to volume resuscitation, reversal of coagulopathy, correction of acidosis and other pertinent resuscitative measures that have become standard of care for surgical ICU patients. In addition to these maneuvers, the patient with an OA will require added attention to fluid status, nutrition, and respiratory mechanics. They should also be monitored for recurrent ACS. The intensivist must focus on optimizing physiology to facilitate closure of the abdomen because prolonged $\mathrm{OA}$ frequently delays extubation, increases the risk for enteroatmospheric fistulae, and increases complications. Independent predictors associated with failure to achieve primary closure include the number of re-explorations, the development of intra-abdominal infection, blood stream infection, acute renal failure, enteric fistula, and Injury Severity Score. Those factors that can be mitigated by intensive care may therefore improve the likelihood of early fascial closure leading to improved outcomes and reduced resource utilization. ${ }^{60}$

The initial step in caring for patients with OA in the ICU is to resuscitate and reverse the "lethal triad" of hypothermia, acidosis, and coagulopathy. This triad was first described by Kashuk in 1982 and refers to the pathophysiology of hemorrhage. ${ }^{61}$ Hypothermia predisposes patients to cardiac dysrhythmias, reduces cardiac output, and affects the offloading of oxygen from cells by shifting the oxygenation hemoglobin saturation curve to the left. ${ }^{62}{ }^{63}$ Approximately $4.6^{\circ} \mathrm{C}$ are lost per hour during a laparotomy, even with the use of warmed intravenous fluids, anesthetics, and air convection blankets. ${ }^{64}$ The amount of heat loss with an OA and a temporary abdominal dressing has not been quantified, but one can assume there is additional insensible heat loss when compared with a closed abdomen. This has a mortality implication with one study identifying a $40 \%$ to $100 \%$ mortality increase in patients with trauma who had a drop in core temperature from $34^{\circ} \mathrm{C}$ to less than $32^{\circ} \mathrm{C}^{65}$. In addition to cardiac effects, hypothermia also affects the clotting cascade. ${ }^{62}$ As body temperature drops, both the prothrombin time and partial thromboplastin time become significantly elevated secondary to enzymatic dysregulation. ${ }^{66}$ Platelet dysfunction also occurs as evidenced by prolonged bleeding times in animal models of hypothermia. ${ }^{62}$ This trauma-induced coagulopathy has been shown to be an independent predictor of multiorgan failure, septic complications, length of ICU stay, and mortality. ${ }^{67}$ As hemorrhage continues and tissues become hypoperfused, acidosis develops. The ability to clear this acidosis, as analyzed by lactate clearance, has been correlated to survival. In 1993, Abramson evaluated patients with trauma and found that if lactate was cleared within 24 hours, there was a $100 \%$ survival rate. If not, only $14 \%$ of patients would survive. ${ }^{68}$ Since then, lactate has been well described as a marker of oxygen delivery, morbidity, and mortality in shock. When severe acidosis occurs $(\mathrm{pH}<7.1)$, coagulopathy worsens, continuing the downward spiral of hemorrhage. ${ }^{69}$ The challenge for the intensivist is to facilitate this rapid clearance of lactate through efficient resuscitation while keeping in mind that overzealous resuscitation may lead to increasing abdominal hypertension and prolong the OA.

The intensivist should be aware of this triad and expeditiously correct these parameters to improve patient outcomes, particularly for patients who undergo DCS. Attention to body temperature should be maintained, and efforts to keep the patient warm should include removing wet linen, elevating the ambient temperature, warming ventilator circuits, judicial use of convection blankets, and use of warm intravenous fluids. A reasonable goal is to obtain a core temperature of $37^{\circ} \mathrm{C}$ within 4 hours of arrival to the ICU. ${ }^{63}$ Coagulopathy should be corrected with the use of blood products to achieve a goal PT $<15$, platelets $>100 \mathrm{k}$, and fibrinogen $>100 .{ }^{637071}$ It has been shown that early administration of plasma and platelets should be given in coordination with RBC transfusions exceeding more than 10 units in 24 hours. $^{7273,73}$ A recent review examined this ratio-driven resuscitation in combat casualties and found that it was an independent predictor of early fascial closure after laparotomy (2.4 days vs 7.2 days, $p=0.004) .^{74}$ The exact ratio of pRBCs:FFP:platelets historically had been recommended at somewhere between 2:1:1 and 1:1:1 based on the randomized PROPPR trial, but the precise ratio is still debated..$^{75}$ More recently, the use of thromboelastometry to guide product administration during DCR has been used. Data suggest that it can rapidly identify hyperfibrinolysis and predict the need for massive transfusion, but there are no studies that validate its use as an end point of resuscitation. ${ }^{76-79}$ Lactate should be monitored; failure of lactate to clear with resuscitation should prompt the intensivist to consider a missed injury, extremity compartment syndrome, ongoing hemorrhage, or the development of ACS. ${ }^{63} 71$ If evidence for these complications is present, or if the patient requires more than 2 units of RBCs per hour for 3 hours, consideration for reoperation or angiography should be given. ${ }^{6370}$

\section{MANAGING THE PATIENT REQUIRING EMERGENT BEDSIDE DECOMPRESSION}

The patient who develops ACS in the ICU can rapidly become unstable. These patients may become progressively hypotensive with transient response to fluid boluses, which lead to worsening ACS that, if unrecognized, leads to reduced pulmonary compliance and worsening respiratory acidosis, which contributes to the metabolic acidosis occurring as a result of hypoperfusion and in some instances hyperchloremia from overzealous use of normal saline. The resulting drop in $\mathrm{pH}$ further compromises cardiac output leading to further hypotension and hypoperfusion. Once recognized that ACS is present and the abdomen is opened at the bedside, the intensivist must be present to manage the patient's rapidly changing physiology. When managing the ventilator for these patients, it must be remembered that pulmonary damage occurring from high ventilator pressures occurs as a result of elevated pressures within the lung parenchyma; however, in ACS, the transpulmonary pressure is elevated, and overdistension of alveoli from these elevated pressures does not 
occur as it does from unopposed pressures delivered from high ventilator settings in a patient without ACS. Dropping tidal volumes to maintain lower airway pressures when a patient is developing ACS will lead to significant respiratory acidosis and hypoxia, which may be fatal in the acute setting as preparations are made to open the abdomen. Likewise, once the abdomen is opened, the ventilator must be immediately adjusted to maintain an appropriate tidal volume that does not overexpand the lung with the rapidly decompressed abdomen. Significant acid load can be washed out of the abdomen and enter the circulation, which can result in cardiovascular collapse. To combat this, maintaining an initial high minute ventilation and administering bicarbonate and calcium can combat these effects. Pulmonary compliance may also be affected by associated large pleural effusions that may benefit from thoracostomy drainage. Pulmonary hypertension secondary to hypercarbia and sepsis-induced myocardial dysfunction may lead to right ventricular overload, which can be acutely worsened with the rapid increase in flow that results from opening the abdomen. This may necessitate the use of dobutamine or milrinone to improve ventricular function while simultaneously reducing pulmonary vascular pressure.

\section{FLUID STATUS AND INTRA-ABDOMINAL PHYSIOLOGY}

To understand the fluid shifts that occur with an OA, one must be familiar with intra-abdominal physiology. In shock states, intravascular volume is preferentially shunted away from the gastrointestinal tract to vital organs such as the brain and heart, increasing the risk for intestinal hypoperfusion/ischemia. This can be exacerbated by several additional factors that a patient with an OA may experience. For example, elevated intra-abdominal pressures in ACS or intra-abdominal packing in the patient with hemorrhagic trauma may impair mesenteric venous return and lead to congestive intestinal ischemia. As volume is restored during resuscitation and the compromised bowel is reperfused, free-radical mucosal damage may occur. With this increased mucosal permeability comes increasing bowel wall edema. ${ }^{34}$ There is also a systemic efflux of cytokines that may contribute to multiorgan failures. ${ }^{80}$ Elevated CVPs that may occur during resuscitation have also been implicated in worsening intestinal edema through inhibition of lymphatic outflow via the cisterna chyli. ${ }^{81}$

The primary goal of the intensivist when managing patients with OA is to balance resuscitative efforts with attempts to minimize volume overload and visceral edema. This balance is essential to optimize the surgical success of primary fascial closure. It has been shown that $60 \%$ to $91 \%$ of patients treated with OA will achieve primary fascial closure. ${ }^{82-84}$ Patients who are unable to have the fascia primarily closed will likely need to have abdominal wall reconstruction with or without prosthetics or will be committed to a large incisional ventral hernia with anticipated secondary granulation of the wound. Failure to achieve primary fascial closure has been associated with increased risk of infections and enteroatmospheric fistulas. ${ }^{82}$ It has also been independently associated with mortality. ${ }^{85}$ One study found that a fluid-related weight gain $>10 \%$ led to only $39 \%$ primary fascial closure rate. ${ }^{82}$ In addition to volume overload, other risk factors for failure of primary closure include the development of intra-abdominal abscesses, the presence of enterocutaneous fistulae, the longer duration of $\mathrm{OA}$, the greater number of serial abdominal explorations, and worse base deficits. ${ }^{8687}$

Understanding the pathophysiology of an OA is the first step to managing fluid status; the next step for the intensivist is to quantify intravascular volume. Although literature has raised questions on the predictability and validity of "static" indices such as CVP and pulmonary artery occlusion pressure (PAOP) in ACS, the data on techniques to assess intravascular volume with an OA are limited. A study from 1999 sought to examine these parameters in patients with OA. They suggest that in both patients with IAH and those subsequently decompressed with an OA, right ventricular end diastolic volume index (RVEDVI) is the most accurate predictor of intravascular volume. CVP and PAOP are less reliable in both of these scenarios. However, the authors were unable to provide an "optimal" RVEDVI to target during resuscitation but instead recommended aiming for the clinical restoration of end-organ perfusion with markers such as lactate. ${ }^{88}$ The use of the Vigileo monitor to evaluate "dynamic" indices, specifically stroke volume variation (SVV), in patients with an OA has also been described. A retrospective study in 2013 compared the continuous use of SVV to guide crystalloid administration to the standard use of static indices such as cardiac echocardiography or lactate to assess resuscitation. They found a statistically significant improvement in time to primary fascial closure by an average of 1 day for patients resuscitated using the SVV as an end point. There was also a decrease in the time to lactate clearance by 0.8 days. The patients in these two groups were well matched for age, APACHE II score, and underlying etiology. It was hypothesized that the reason for these findings is that continuous assessment of volume status helps the intensivist more strictly titrate resuscitation to avoid hypoperfusion or volume overload. ${ }^{89}$

Studies examining strategies to minimize visceral edema in the $\mathrm{OA}$ are also limited. Given the protein loss associated with $\mathrm{OA}$, albumin as a resuscitative solution has potential therapeutic benefit. However, no randomized studies examining this exist in the population of patiens with OA, and intensivists are left to extrapolate data from generalized ICU populations. ${ }^{90}$ One small, observational study examined the use of hypertonic saline as a resuscitative solution for patients with OA. Patients receiving $3 \%$ saline had a higher (but not statistically significant) rate of primary fascial closure compared with patients receiving normal saline or LR solution (100\% vs $76 \%)$. The authors hypothesized that the reason for this difference was due to the shift of fluid to the intravascular space with hypertonic saline and due to its potential ability to attenuate the inflammatory response. ${ }^{91}$

Forced diuresis with a furosemide drip has also been studied in patients with OA but failed to show any improvement in fascial closure rates $(68.4 \%$ primary closure in patients receiving furosemide, $64.0 \%$ in those without furosemide, $\mathrm{p}=0.669$ ). However, this was a small retrospective study that did not control for severity of injury, did not standardize furosemide dosing, and did not quantify actual fluid balance. ${ }^{92}$ Further studies to identify the optimal fluid strategy and type in patients with OA that promote early closure are needed. Until these studies are performed, it is reasonable for the intensivist to use dynamic indices to provide tight fluid balance that allows for timely resuscitation while minimizing edema.

\section{NUTRITION}

It is well known that critical illness is associated with a catabolic state and that nutrition in the ICU patient is exceedingly important but often overlooked. The Society of Critical Care Medicine (SCCM) has partnered with the American Society for Parenteral and Enteral Nutrition to provide nutritional guidelines for the general ICU population. They advise that full enteral nutrition to meet goal metabolic needs be initiated within 24 to 48 hours when feasible. This has been shown to maintain gut integrity, modulate the systemic 
inflammatory response, and reduce both mortality and infectious morbidity. ${ }^{93}$

For the same reasons as a general ICU patient, patients with OA will require nutritional supplementation. However, the patient with OA will have increased fluid, electrolyte, and protein requirements because of large volume losses of these substrates through their abdominal wound. Failure to recognize these losses in calculations of nitrogen balance and caloric needs will lead to underfeeding. It is estimated that $2 \mathrm{~g}$ to $4.6 \mathrm{~g}$ of nitrogen are lost per liter of abdominal fluid output depending on the type of temporary abdominal closure. ${ }^{94}{ }^{95}$ Measurements of peritoneal fluid from OAs also demonstrates a significant amount of potassium, phosphorus, magnesium, and calcium, a finding that must be taken into account when providing electrolyte replacements. ${ }^{95}$

Early fears with OA were that patients would experience a severe paralytic ileus with exposed viscera and that feeding may exacerbate bowel edema. However, this has been well refuted in the literature, and early enteral feeds are now considered safe and beneficial assuming there are no major contraindications, such as intestinal discontinuity. ${ }^{9697}$ Not only are enteral feeds safe in the OA, they are associated with a lower rate of ventilator-associated pneumonia (VAP) (43.8\% vs $72.1 \%),{ }^{98}$ earlier primary abdominal closure (74\% vs $49 \%),{ }^{99}$ and lower rates of fistulas (9\% vs $26 \%) .{ }^{98-100}$ It is unknown whether the link between early feeds and reduced incidence of VAP may be secondary to earlier extubation after earlier abdominal closure versus a direct result of intestinal flora modification.

The Western Trauma Association (WTA) published a large multicenter trial in 2012 comparing patients who received enteral nutrition (EN) prior to abdominal closure to those kept nil per os (NPO) for the duration of their OA. Specifically, in patients without intestinal injury, time to fascial closure was longer in the EN group (7 days vs 4 days), but overall closure rate was significantly higher ( $84 \%$ vs $50 \%)$. This differs from the earlier study by Collier. One hypothesis for this variation is the presence of multiple confounding variables that may not have been accounted for in earlier studies such as the presence of intestinal injury or etiology of OA (trauma, ACS, intra-abdominal sepsis, etc). Mortality was also lower in the EN group compared with those kept NPO (10\% vs $23 \%$ ). The presence of intestinal injury in the WTA study led to a significantly lower incidence of fascial closure with EN (55\% vs $78 \%$ ) and a higher abdominal complication rate (45\% vs 30\%). However, intestinal injury did not have a significant effect on overall mortality. Questions such as location of feeds (stomach vs small intestine), amount of enteral nutrition (goal tube feeds vs trophic feeds), and use of specialized formulas were not addressed in this study and have yet to be investigated among patients with OA. ${ }^{101}$ New evidence in rat models has demonstrated that high-fat enteral nutrition may reduce intestinal mucosal barrier breakdown after peritoneal air exposure, but this has yet to be examined in humans. ${ }^{102}$

\section{VENTILATOR MECHANICS AND SEDATION}

The driving principle of ventilation in patients with $\mathrm{OA}$ is that support should be tailored to the specific disease process. Although most patients who require an OA have underlying diseases that mandate intubation and mechanical ventilation, the presence of $\mathrm{OA}$ in and of itself does not require that a patient receive additional ventilator support. ${ }^{103}$ There have been several reports of patients with an $\mathrm{OA}$ and temporary abdominal closure being extubated and ambulatory with a low incidence of evisceration. Although the integrity of the abdominal wall contributes to the stability of normal respiratory mechanics by maintaining negative subdiaphragmatic pressures (a factor that prevents rapid loss of volume during expiration), it has been shown that respiratory musculature can compensate for these mechanical changes. ${ }^{104}$

However, because patients with OA have a significant risk of developing acute respiratory distress syndrome (ARDS) early in their ICU course, extubation of such patients should be done cautiously. One study found that $14 \%$ of trauma patients undergoing DCS developed ARDS. This was correlated with higher volumes of both crystalloid and colloid infusions; a patient who received $>10 \mathrm{~L}$ of fluid during their first 24 hours after injury had a $10 \%$ increased risk of developing ARDS. ${ }^{105}$ Other risk factors for ARDS that are often seen in patients with OA include sepsis, aspiration, pneumonia, drugs and alcohol, and acute pancreatitis. Intestinal ischemia-reperfusion syndrome has also been shown to be a risk factor for ARDS based on the systemic release of cytokines as previously discussed. ${ }^{47}$ It has been proposed that, for patients with multiple ARDS risk factors, pre-emptive lung protective ventilation strategies should be considered. ${ }^{34106}$

Standard sedation and pain control should be used for patients who are intubated with an OA. Light sedation as defined by a score of -2 to 0 on the Richmond Agitation-Sedation Scale should be sufficient to keep the temporary abdominal dressing in place. ${ }^{103}$

\section{ADDITIONAL CONSIDERATIONS ACS in the $O A$}

Although the ideal temporary abdominal dressing is tensionfree, patients with an OA remain at risk for recurrent ACS, especially in the setting of ongoing resuscitation. The reported incidence of ACS after DCS is $6 \%$ to $14 \%$. The intensivist should be aware of this fact and continue to monitor bladder pressures for at-risk patients. Increasing bladder pressures associated with new organ failure should lead the surgeon to consider opening the temporary dressing for the purposes abdominal decompression. ${ }^{107} 108$

\section{Infectious complications}

It has been shown that patients with an OA are at an increased risk of infectious complications. One study found that $25 \%$ developed a wound infection, a deep abdominal abscess, or an intestinal fistula. ${ }^{87}$ These infectious complications increased after 8 days of having an $\mathrm{OA}$ and significantly reduce the ability to achieve primary fascial closure. ${ }^{84} 86$ Of course, it is unknown if it is the OA that contributes to the increased risk of subsequent intra-abdominal infection or the underlying pathophysiology of the initial infection that necessitates the abdomen to remain open leading to further infection. Regardless of the causal pathway, intra-abdominal infections decrease the rate of primary fascial closure after an OA, as do other systemic infections such as pneumonia or bacteremia. ${ }^{109}$ The AAST Open Abdomen Study group found that patients who were unable to achieve primary closure were more likely to have bloodstream infections (18.4\% vs 6.5\%). ${ }^{60}$ The intra-abdominal microbial colonization of patients with OA measured during dressing changes demonstrates that $78 \%$ of patients had positive bacterial cultures, most commonly with Gram-positive cocci and Gram-negative bacilli. Although the differences between the ability to achieve primary fascial closure and the rates of fascial dehiscence between colonized and non-colonized patients were not statistically different, there was a trend suggesting that colonized patients had worse outcomes. OA duration and number of dressing changes predispose patients to infectious complications, again emphasizing 
the need to achieve abdominal closure rapidly when physiology permits it. ${ }^{110}$

Despite the evidence that the development of an infection leads to worse outcomes in patients with OA, there is very little literature on prophylactic antibiotics for patients with an OA without evidence of infection. The current recommendations are to tailor antibiotics to the disease process and to use quality improvement initiatives to reduce healthcare-associated infections such as VAP or catheter-associated bloodstream infections. ${ }^{60103}$

\section{Returning to the operating room}

Pommerening et al examined the timing to the first take back after DCS in patients with trauma. They found that for every hour delay after the first 24 hours, there was a $1.1 \%$ decrease in the odds of primary fascial closure. In addition, there was a trend toward increasing intra-abdominal complications in patients returning after 48 hours. The authors recommend that the first return to the OR take place ideally within 24 hours and no later than 48 hours after the initial laparotomy. ${ }^{111}$ Earlier return to the operating room should be considered for the patient in persistent hemorrhagic shock who requires more than 2 units of RBCs per hour for 3 hours. ${ }^{63} 70$ Tertiary ACS as manifested by increasing bladder pressures associated with new organ failure would be the other indication for earlier re-exploration. ${ }^{107}{ }^{108} \mathrm{In}$ regards to the timing of definitive closure, the goal should be as early as possible when edema resides, hemorrhage is controlled with packing removal, and definitive intestinal anastomoses have been performed. ${ }^{112}$ Miller et al demonstrated that complications significantly increased if primary abdominal closure was not performed after 8 days from the time of the initial laparotomy ( $12 \%$ vs $52 \%) .{ }^{87}$ If definitive abdominal closure cannot be performed prior to this time, progressive closure should be attempted with each reoperation. ${ }^{112}$

\section{CONCLUSION}

OA as part of DCR can be a lifesaving maneuvre; however, it is a treatment option that poses certain complications and challenges. Minimizing OA duration is beneficial, and the intensivist's role is crucial to creating the physiologic environment that promotes early closure. In addition to standard ICU principles, the patient with $\mathrm{OA}$ will require tight management of fluids to ensure resuscitation without volume overload perhaps with hypertonic saline, although this requires further study. Consideration of more advanced hemodynamic monitoring to guide fluid resuscitation may yield earlier closure. Early nutrition, particularly in patients with OA without intestinal injury, should be maximized to account for additional protein losses. The patient should be monitored for systemic signs of inflammation such as ARDS, intra-abdominal infection, and recurrent ACS, which should be promptly managed. Antibiotics should be tailored to underlying infections. Attention to these factors may lead to earlier closure, reduced intra-abdominal and infectious complications, and reduced resource utilization.

Contributors Both EC and RN performed the literature searches and summaries incorporated into the manuscript. Both authors participated in the writing of the manuscript.

\section{Competing interests None declared.}

Provenance and peer review Commissioned; externally peer reviewed.

Open Access This is an Open Access article distributed in accordance with the Creative Commons Attribution Non Commercial (CC BY-NC 4.0) license, which permits others to distribute, remix, adapt, build upon this work non-commercially, and license their derivative works on different terms, provided the original work is properly cited and the use is non-commercial. See: http://creativecommons.org/ licenses/by-nc/4.0/

(C) Article author(s) (or their employer(s) unless otherwise stated in the text of the article) 2017. All rights reserved. No commercial use is permitted unless otherwise expressly granted.

\section{REFERENCES}

1 Rezende-Neto J, Rice T, Abreu ES, Rotstein O, Rizoli S. Anatomical, physiological, and logistical indications for the open abdomen: a proposal for a new classification system. World J Emerg Surg 2016;11:28.

2 Roberts DJ, Ball CG, Feliciano DV, Moore EE, Ivatury RR, Lucas CE, Fabian TC, Zygun DA, Kirkpatrick AW, Stelfox HT. History of the innovation of damage control for management of trauma patients: 1902-2016. Ann Surg 2017;265:1034-44.

3 Burch JM, Ortiz VB, Richardson RJ, Martin RR, Mattox KL, Jordan GL. Abbreviated laparotomy and planned reoperation for critically injured patients. Ann Surg 1992:215:476-84.

4 Rotondo MF, Schwab CW, McGonigal MD, Phillips GR, Fruchterman TM, Kauder DR, Latenser BA, Angood PA. 'Damage control': an approach for improved survival in exsanguinating penetrating abdominal injury. J Trauma 1993;35:375-82.

5 Lee JC, Peitzman AB. Damage-control laparotomy. Curr Opin Crit Care 2006; 12:346-50

6 Cirocchi R, Montedori A, Farinella E, Bonacini I, Tagliabue L, Abraha I. Damagecontrol surgery for abdominal trauma. In: Cirocchi R, ed. Cochrane Database ofSystematic Reviews. Chichester, UK: John Wiley \& Sons, Ltd, 2013:CD007438.

7 Diaz JJ, Cullinane DC, Dutton WD, Jerome R, Bagdonas R, Bilaniuk JW, Bilaniuk JO, Collier BR, Como JJ, Cumming J, et al. The management of the open abdomen in trauma and emergency general surgery: part 1-damage control. J Trauma 2010;68:1425-38.

8 Harvin JA, Wray CJ, Steward J, Lawless RA, McNutt MK, Love JD, Moore LJ, Wade CE, Cotton BA, Holcomb JB. Control the damage: morbidity and mortality after emergent trauma laparotomy. Am J Surg 2016;212:34-9.

9 Brenner M, Bochicchio G, Bochicchio K, Ilahi O, Rodriguez E, Henry S, Joshi M, Scalea T. Long-term impact of damage control laparotomy: a prospective study. Arch Surg 2011:146:395-9.

10 Cotton BA, Au BK, Nunez TC, Gunter OL, Robertson AM, Young PP. Predefined massive transfusion protocols are associated with a reduction in organ failure and postinjury complications. J Trauma 2009;66:41-9.

11 Cotton BA, Gunter OL, Isbell J, Au BK, Robertson AM, Morris JA, St Jacques P, Young PP. Damage control hematology: the impact of a trauma exsanguination protocol on survival and blood product utilization. J Trauma 2008;64:1177-83.

12 Cotton BA, Reddy N, Hatch QM, LeFebvre E, Wade CE, Kozar RA, Gill BS, Albarado $\mathrm{R}$, McNutt MK, Holcomb JB. Damage control resuscitation is associated with a reduction in resuscitation volumes and improvement in survival in 390 damage control laparotomy patients. Ann Surg 2011;254:598-605.

13 Holcomb JB, Jenkins D, Rhee P, Johannigman J, Mahoney P, Mehta S, Cox ED, Gehrke MJ, Beilman GJ, Schreiber M, et al. Damage control resuscitation: directly addressing the early coagulopathy of trauma. J Trauma 2007;62:307-10.

14 Hodgetts TJ, Mahoney PF, Kirkman E. Damage control resuscitation. J R Army Med Corps 2007;153:299-300.

15 Lamb CM, MacGoey P, Navarro AP, Brooks AJ. Damage control surgery in the era of damage control resuscitation. Br J Anaesth 2014;113:242-9.

16 Malbrain ML, Cheatham ML, Kirkpatrick A, Sugrue M, Parr M, De Waele J, Balogh Z, Leppäniemi A, Olvera C, Ivatury R, et al. Results from the International Conference of Experts on Intra-abdominal Hypertension and Abdominal Compartment Syndrome. I. Definitions. Intensive Care Med 2006:32:1722-32.

17 Cheatham ML, Malbrain ML, Kirkpatrick A, Sugrue M, Parr M, De Waele J, Balogh Z, Leppäniemi A, Olvera C, Ivatury $R$, et al. Results from the International Conference of Experts on Intra-abdominal Hypertension and Abdominal Compartment Syndrome. II. Recommendations. Intensive Care Med 2007:33:951-62.

18 Cheatham ML, White MW, Sagraves SG, Johnson JL, Block EF. Abdominal perfusion pressure: a superior parameter in the assessment of intra-abdominal hypertension. $J$ Trauma 2000;49:621-7.

19 Malbrain ML, Chiumello D, Pelosi P, Bihari D, Innes R, Ranieri VM, Del Turco M, Wilmer A, Brienza N, Malcangi V, et al. Incidence and prognosis of intraabdominal hypertension in a mixed population of critically ill patients: a multiple-center epidemiological study. Crit Care Med 2005;33:315-22.

20 Hakobyan RV, Mkhoyan GG. Epidural analgesia decreases intraabdominal pressure in postoperative patients with primary intra-abdominal hypertension. Acta Clin Belg 2008;63:86-92.

21 Corcos AC, Sherman HF. Percutaneous treatment of secondary abdominal compartment syndrome. J Trauma 2001;51:1062-4.

22 Parra MW, Al-Khayat H, Smith HG, Cheatham ML. Paracentesis for resuscitationinduced abdominal compartment syndrome: an alternative to decompressive laparotomy in the burn patient. J Trauma 2006:60:1119-21.

23 Cheatham ML, Safcsak K. Percutaneous catheter decompression in the treatment of elevated intraabdominal pressure. Chest 2011;140:1428-35. 
24 Oda J, Ueyama M, Yamashita K, Inoue T, Noborio M, Ode Y, Aoki Y, Sugimoto H. Hypertonic lactated saline resuscitation reduces the risk of abdominal compartment syndrome in severely burned patients. J Trauma 2006;60:64-71.

25 O'Mara MS, Slater H, Goldfarb IW, Caushaj PF. A prospective, randomized evaluation of intra-abdominal pressures with crystalloid and colloid resuscitation in burn patients. J Trauma 2005;58:1011-8.

26 De Waele J, Delaet I, Hoste E, Verholen E, Blot S. The effect of neuromuscular blockers on intraabdominal pressure. Crit Care Med 2006;34:A70.

27 De Laet I, Hoste E, Verholen E, De Waele JJ. The effect of neuromuscular blockers in patients with intra-abdominal hypertension. Intensive Care Med 2007;33:1811-4.

28 Cheatham ML. Nonoperative management of intraabdominal hypertension and abdominal compartment syndrome. World J Surg 2009;33:1116-22.

29 Ertel W, Oberholzer A, Platz A, Stocker R, Trentz O. Incidence and clinical pattern of the abdominal compartment syndrome after "damage-control " laparotomy in 311 patients with severe abdominal and/or pelvic trauma. Crit Care Med 2000;28:1747-53.

30 De Waele JJ, Hoste EA, Malbrain ML. Decompressive laparotomy for abdominal compartment syndrome--a critical analysis. Crit Care 2006;10:R51.

31 Scalea TM, Bochicchio GV, Habashi N, McCunn M, Shih D, McQuillan K, Aarabi B. Increased intra-abdominal, intrathoracic, and intracranial pressure after severe brain injury: multiple compartment syndrome. J Trauma 2007;62:647-56.

32 Joseph DK, Dutton RP, Aarabi B, Scalea TM. Decompressive laparotomy to treat intractable intracranial hypertension after traumatic brain injury. J Trauma 2004:57:687-95

33 Coccolini F, Biffl W, Catena F, Ceresoli M, Chiara O, Cimbanassi S, Fattori L, Leppaniemi A, Manfredi R, Montori $G$, et al. The open abdomen, indications, management and definitive closure. World J Emerg Surg 2015;10:32.

34 Griggs C, Butler K. Damage Control and the Open Abdomen: Challenges for the Nonsurgical Intensivist. J Intensive Care Med 2016;31:567-76.

35 Mentula P, Hienonen P, Kemppainen E, Puolakkainen P, Leppäniemi A. Surgical decompression for abdominal compartment syndrome in severe acute pancreatitis. Arch Surg 2010;145:764-9.

36 Sun ZX, Huang HR, Zhou H. Indwelling catheter and conservative measures in the treatment of abdominal compartment syndrome in fulminant acute pancreatitis. World J Gastroenterol 2006:12:5068-70.

37 Park S, Lee S, Lee HD, Kim M, Kim K, Jeong Y, Park SM. Abdominal compartment syndrome in severe acute pancreatitis treated with percutaneous catheter drainage. Clin Endosc 2014;47:469.

38 Radenkovic DV, Johnson CD, Milic N, Gregoric P, Ivancevic N, Bezmarevic M, Bilanovic D, Cijan V, Antic A, Bajec D. Interventional Treatment of Abdominal Compartment Syndrome during Severe Acute Pancreatitis: Current Status and Historical Perspective. Gastroenterol Res Pract 2016;2016:1-6.

39 Peng T, Dong LM, Zhao X, Xiong JX, Zhou F, Tao J, Cui J, Yang ZY. Minimally invasive percutaneous catheter drainage versus open laparotomy with temporary closure for treatment of abdominal compartment syndrome in patients with early-stage severe acute pancreatitis. J Huazhong Univ Sci Technolog Med Sci 2016;36:99-105.

40 Ivatury RR, Nallathambi M, Rao PM, Rohman M, Stahl WM. Open management of the septic abdomen: therapeutic and prognostic considerations based on APACHE II. Crit Care Med 1989;17:511-7.

41 Robledo FA, Luque-de-León E, Suárez R, Sánchez P, de-la-Fuente M, Vargas A, Mier J. Open versus closed management of the abdomen in the surgical treatment of severe secondary peritonitis: a randomized clinical trial. Surg Infect 2007;8:63-72.

42 Bleszynski MS, Chan T, Buczkowski AK. Open abdomen with negative pressure device vs primary abdominal closure for the management of surgical abdominal sepsis: a retrospective review. Am J Surg 2016;211:926-32.

43 Sartelli M, Abu-Zidan FM, Ansaloni L, Bala M, Beltrán MA, Biffl WL, Catena F, Chiara O, Coccolini F, Coimbra R, et al. The role of the open abdomen procedure in managing severe abdominal sepsis: WSES position paper. World J Emerg Surg 2015;10:35.

44 Sohn M, Agha A, Heitland W, Gundling F, Steiner P, lesalnieks I. Damage control strategy for the treatment of perforated diverticulitis with generalized peritonitis. Tech Coloproctol 2016;20:577-83.

45 Loftus TJ, Jordan JR, Croft CA, Smith RS, Efron PA, Mohr AM, Moore FA, Brakenridge SC. Temporary abdominal closure for trauma and intra-abdominal sepsis. J Trauma Acute Care Surg 2017:82:345-50.

46 Becher RD, Peitzman AB, Sperry JL, Gallaher JR, Neff LP, Sun Y, Miller PR, Chang MC Damage control operations in non-trauma patients: defining criteria for the staged rapid source control laparotomy in emergency general surgery. World J Emerg Surg 2016;11:10.

47 Shah SK, Jimenez F, Letourneau PA, Walker PA, Moore-Olufemi SD, Stewart RH, Laine GA, Cox CS. Strategies for modulating the inflammatory response after decompression from abdominal compartment syndrome. Scand J Trauma Resusc Emerg Med 2012;20:25

48 Kirkpatrick AW, Roberts DJ, Faris PD, Ball CG, Kubes P, Tiruta C, Xiao Z, Holodinsky JK, McBeth PB, Doig CJ, et al. Active negative pressure peritoneal therapy after abbreviated laparotomy. Ann Surg 2015;262:38-46.

49 Roberts DJ, Jenne CN, Ball CG, Tiruta C, Léger C, Xiao Z, Faris PD, McBeth PB, Doig $\mathrm{CJ}$, Skinner $C R$, et al. Efficacy and safety of active negative pressure peritoneal therapy for reducing the systemic inflammatory response after damage control laparotomy (the intra-peritoneal vacuum trial): study protocol for a randomized controlled trial. Trials 2013;14:141

50 Adkins AL, Robbins J, Villalba M, Bendick P, Shanley CJ. Open abdomen management of intra-abdominal sepsis. Am Surg 2004;70:137-40.

51 Djavani Gidlund K, Wanhainen A, Björck M. Intra-abdominal hypertension and abdominal compartment syndrome after endovascular repair of ruptured abdominal aortic aneurysm. Eur J Vasc Endovasc Surg 2011:41:742-7.

52 Rasmussen TE, Hallett JW, Noel AA, Jenkins G, Bower TC, Cherry KJ, Panneton JM, Gloviczki P. Early abdominal closure with mesh reduces multiple organ failure after ruptured abdominal aortic aneurysm repair: guidelines from a 10-year case-control study. J Vasc Surg 2002;35:246-53.

53 Kimball EJ, Adams DM, Kinikini DV, Mone MC, Alder SC. Delayed abdominal closure in the management of ruptured abdominal aortic aneurysm. Vascular 2009:17:309-15.

54 Djavani K, Wanhainen A, Valtysson J, Björck M. Colonic ischaemia and intraabdominal hypertension following open repair of ruptured abdominal aortic aneurysm. Br J Surg 2009;96:621-7.

55 Atema JJ, Gans SL, Boermeester MA. Systematic review and meta-analysis of the open abdomen and temporary abdominal closure techniques in non-trauma patients. World J Surg 2015;39:912-25.

56 Frazee RC, Abernathy SW, Jupiter DC, Hendricks JC, Davis M, Regner JL, Isbell T, Smith RW, Smythe WR. Are commercial negative pressure systems worth the cost in open abdomen management? J Am Coll Surg 2013:216:730-3.

57 Bruhin A, Ferreira F, Chariker M, Smith J, Runkel N. Systematic review and evidence based recommendations for the use of negative pressure wound therapy in the open abdomen. Int J Surg 2014;12:1105-14.

58 Carlson GL, Patrick H, Amin Al, McPherson G, MacLennan G, Afolabi E, Mowatt G, Campbell B. Management of the Open Abdomen. Ann Surg 2013;257:1154-9.

59 Lindstedt S, Hansson J, Hlebowicz J. Comparative study of the microvascular blood flow in the intestinal wall during conventional negative pressure wound therapy and negative pressure wound therapy using paraffin gauze over the intestines in laparostomy. Int Wound J 2012;9:150-5.

60 Dubose JJ, Scalea TM, Holcomb JB, Shrestha B, Okoye O, Inaba K, Bee TK, Fabian TC, Whelan J, Ivatury RR. Open abdominal management after damage-control laparotomy for trauma: a prospective observational American Association for the Surgery of Trauma multicenter study. J Trauma Acute Care Surg 2013:74:113-20.

61 Kashuk JL, Moore EE, Millikan JS, Moore JB. Major abdominal vascular trauma--a unified approach. J Trauma 1982:22:672-9.

62 Rotondo MF, Zonies DH. The damage control sequence and underlying logic. Surg Clin North Am 1997:77:761-77.

63 Sagraves SG, Toschlog EA, Rotondo MF. Damage control surgery--the intensivist's role. J Intensive Care Med 2006;21:5-16.

64 Burch JM, Denton JR, Noble RD. Physiologic rationale for abbreviated laparotomy. Surg Clin North Am 1997;77:779-82.

65 Jurkovich GJ, Greiser WB, Luterman A, Curreri PW. Hypothermia in trauma victims: an ominous predictor of survival. J Trauma 1987;27:1019-24.

66 Rohrer MJ, Natale AM. Effect of hypothermia on the coagulation cascade. Crit Care Med 1992;20:1402-5

67 Davenport R, Khan S. Management of major trauma haemorrhage: treatment priorities and controversies. Br J Haematol 2011;155:537-48.

68 Abramson D, Scalea TM, Hitchcock R, Trooskin SZ, Henry SM, Greenspan J. Lactate clearance and survival following injury. J Trauma 1993;35:584-9.

69 Davenport R. Pathogenesis of acute traumatic coagulopathy. Transfusion 2013:53:23S-7.

70 Hirshberg A, Mattox KL. Planned reoperation for severe trauma. Ann Surg 1995;222:3-8.

71 Moore EE, Burch JM, Franciose RJ, Offner PJ, Biffl WL. Staged physiologic restoration and damage control surgery. World I Surg 1998:22:1184-91.

72 Zink KA, Sambasivan CN, Holcomb JB, Chisholm G, Schreiber MA. A high ratio of plasma and platelets to packed red blood cells in the first 6 hours of massive transfusion improves outcomes in a large multicenter study. Am J Surg 2009;197:565-70.

73 Borgman MA, Spinella PC, Perkins JG, Grathwohl KW, Repine T, Beekley AC, Sebesta J, Jenkins D, Wade CE, Holcomb JB. The ratio of blood products transfused affects mortality in patients receiving massive transfusions at a combat support hospital. $J$ Trauma 2007:63:805-13.

74 Glaser J, Vasquez M, Cardarelli C, Dunne J, Elster E, Hathaway E, Bograd B, Safford $\mathrm{S}$, Rodriguez $\mathrm{C}$. Ratio-driven resuscitation predicts early fascial closure in the combat wounded. J Trauma Acute Care Surg 2015;79:S188-S192.

75 Davenport R, Curry N, Manson J, De'Ath H, Coates A, Rourke C, Pearse R, Stanworth $\mathrm{S}$, Brohi K. Hemostatic effects of fresh frozen plasma may be maximal at red cell ratios of 1:2. J Trauma 2011;70:90-6.

76 Keene DD, Nordmann GR, Woolley T. Rotational thromboelastometry-guided trauma resuscitation. Curr Opin Crit Care 2013;19:1-12.

77 Holcomb JB, Minei KM, Scerbo ML, Radwan ZA, Wade CE, Kozar RA, Gill BS, Albarado R, McNutt MK, Khan S, et al. Admission rapid thrombelastography can replace conventional coagulation tests in the emergency department: experience with 1974 consecutive trauma patients. Ann Surg 2012;256:476-86. 
78 Khan S, Brohi K, Chana M, Raza I, Stanworth S, Gaarder C, Davenport R. Hemostatic resuscitation is neither hemostatic nor resuscitative in trauma hemorrhage. J Trauma Acute Care Surg 2014;76:561-8.

79 Da Luz LT, Nascimento B, Shankarakutty AK, Rizoli S, Adhikari NK. Effect of

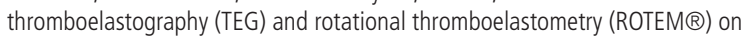
diagnosis of coagulopathy, transfusion guidance and mortality in trauma: descriptive systematic review. Crit Care 2014;18:518.

80 Rezende-Neto JB, Moore EE, Melo de Andrade MV, Teixeira MM, Lisboa FA, Arantes RM, de Souza DG, da Cunha-Melo JR. Systemic inflammatory response secondary to abdominal compartment syndrome: stage for multiple organ failure. J Trauma 2002;53:1121-8

81 Stewart RH, Laine GA. Flow in lymphatic networks: interaction between hepatic and intestinal lymph vessels. Microcirculation 2001:8:221-7.

82 Huang Q, Zhao R, Yue C, Wang W, Zhao Y, Ren J, Li N, Li J. Fluid volume overload negatively influences delayed primary facial closure in open abdomen management. J Surg Res 2014;187:122-7.

83 Patel NY, Cogbill TH, Kallies KJ, Mathiason MA. Temporary abdominal closure: longterm outcomes. J Trauma 2011;70:769-74.

84 Teixeira PG, Salim A, Inaba K, Brown C, Browder T, Margulies D, Demetriades D. A prospective look at the current state of open abdomens. Am Surg 2008;74:891-7.

85 Acosta S, Bjarnason T, Petersson U, Pålsson B, Wanhainen A, Svensson M, Djavani K, Björck M. Multicentre prospective study of fascial closure rate after open abdomen with vacuum and mesh-mediated fascial traction. Br J Surg 2011;98:735-43.

86 Goussous N, Kim BD, Jenkins DH, Zielinski MD. Factors affecting primary fascial closure of the open abdomen in the nontrauma patient. Surgery 2012;152:777-84

87 Miller RS, Morris JA, Diaz JJ, Herring MB, May AK. Complications after 344 damagecontrol open celiotomies. J Trauma 2005;59:1365-74.

88 Cheatham ML, Safcsak K, Block EF, Nelson LD. Preload assessment in patients with an open abdomen. J Trauma 1999;46:16-22.

89 Ghneim MH, Regner JL, Jupiter DC, Kang F, Bonner GL, Bready MS, Frazee R, Ciceri D, Davis ML. Goal directed fluid resuscitation decreases time for lactate clearance and facilitates early fascial closure in damage control surgery. Am J Surg 2013:206:995-1000

90 Finfer S, Bellomo R, Boyce N, French J, Myburgh J, Norton R. A comparison of albumin and saline for fluid resuscitation in the intensive care unit. N Eng/ J Med 2004;350:2247-56

91 Harvin JA, Mims MM, Duchesne JC, Cox CS, Wade CE, Holcomb JB, Cotton BA. Chasing 100\%: the use of hypertonic saline to improve early, primary fascial closure after damage control laparotomy. J Trauma Acute Care Surg 2013;74:426-30

92 Webb LH, Patel MB, Dortch MJ, Miller RS, Gunter OL, Collier BR. Use of a furosemide drip does not improve earlier primary fascial closure in the open abdomen. J Emerg Trauma Shock 2012;5:126.

93 McClave SA, Taylor BE, Martindale RG, Warren MM, Johnson DR, Braunschweig C, McCarthy MS, Davanos E, Rice TW, Cresci GA, et al. Guidelines for the Provision and Assessment of Nutrition Support Therapy in the Adult Critically III Patient: Society of Critical Care Medicine (SCCM) and American Society for Parenteral and Enteral Nutrition (A.S.P.E.N.).JPEN J Parenter Enteral Nutr 2016:40:159-211.

94 Cheatham ML, Safcsak K, Brzezinski SJ, Lube MW. Nitrogen balance, protein loss, and the open abdomen. Crit Care Med 2007;35:127-31.
95 Hourigan LA, Hourigan L, Linfoot JA, Linfoot J, Chung KK, Chung K, Dubick MA, Dubick M, Rivera RL, Rivera R, et al. Loss of protein, immunoglobulins, and electrolytes in exudates from negative pressure wound therapy. Nutr Clin Pract 2010:25:510-6.

96 Cothren CC, Moore EE, Ciesla DJ, Johnson JL, Moore JB, Haenel JB, Burch JM. Postinjury abdominal compartment syndrome does not preclude early enteral feeding after definitive closure. Am J Surg 2004;188:653-8.

97 Byrnes MC, Reicks P, Irwin E. Early enteral nutrition can be successfully implemented in trauma patients with an "open abdomen". Am J Surg 2010;199:359-63.

98 Dissanaike S, Pham T, Shalhub S, Warner K, Hennessy L, Moore EE, Maier RV, O'Keefe $\mathrm{GE}$, Cuschieri J. Effect of immediate enteral feeding on trauma patients with an open abdomen: protection from nosocomial infections. J Am Coll Surg 2008;207:690-7.

99 Collier B, Guillamondegui O, Cotton B, Donahue R, Conrad A, Groh K, Richman J, Vogel T, Miller R, Diaz J. Feeding the open abdomen. JPEN J Parenter Enteral Nutr 2007:31:410-5.

100 Moore SM, Burlew CC. Nutrition Support in the Open Abdomen. Nutr Clin Pract 2016:31:9-13.

101 Burlew CC, Moore EE, Cuschieri J, Jurkovich GJ, Codner P, Nirula R, Millar D, Cohen MJ, Kutcher ME, Haan J, et al. Who should we feed? Western Trauma Association multi-institutional study of enteral nutrition in the open abdomen after injury. $J$ Trauma Acute Care Surg 2012;73:1380-8.

102 Tan SJ, Yu C, Yu Z, Lin ZL, Wu GH, Yu WK, Li JS, Li N. High-fat enteral nutrition reduces intestinal mucosal barrier damage after peritoneal air exposure. I Surg Res 2016;202:77-86

103 Dutton WD, Diaz JJ, Miller RS. Critical care issues in managing complex open abdominal wound. J Intensive Care Med 2012:27:161-71.

104 Mondal P, Abu-Hasan M, Saha A, Pitts T, Rose M, Bolser DC, Davenport PW. Effect of laparotomy on respiratory muscle activation pattern. Physiol Rep 2016:4:e12668.

105 Zielinski MD, Jenkins D, Cotton BA, Inaba K, Vercruysse G, Coimbra R, Brown CV, Alley DE, DuBose J, Scalea TM. Adult respiratory distress syndrome risk factors for injured patients undergoing damage-control laparotomy: AAST multicenter post hoc analysis. J Trauma Acute Care Surg 2014;77:886-91.

106 Sadowitz B, Jain S, Kollisch-Singule M, Satalin J, Andrews P, Habashi N, Gatto LA Nieman G. Preemptive mechanical ventilation can block progressive acute lung injury. World J Crit Care Med 2016:5:74.

107 Ivatury RR. Update on open abdomen management: achievements and challenges World J Surg 2009;33:1150-3.

108 Gracias VH, Braslow B, Johnson J, Pryor J, Gupta R, Reilly P, Schwab CW. Abdominal compartment syndrome in the open abdomen. Arch Surg 2002;137:1298-300.

109 Vogel TR, Diaz JJ, Miller RS, May AK, Guillamondegui OD, Guy JS, Morris JA. The open abdomen in trauma: do infectious complications affect primary abdominal closure? Surg Infect 2006;7:433-41

110 Rasilainen SK, Juhani MP, Kalevi LA. Microbial colonization of open abdomen in critically ill surgical patients. World J Emerg Surg 2015;10:25

111 Pommerening MJ, DuBose JJ, Zielinski MD, Phelan HA, Scalea TM, Inaba K, Velmahos GC, Whelan JF, Wade CE, Holcomb JB, et al. Time to first take-back operation predicts successful primary fascial closure in patients undergoing damage control laparotomy. Surgery 2014;156:431-8.

112 Demetriades D. Total management of the open abdomen. Int Wound J 2012;9(Suppl 1):17-24. 